\title{
Das Bewegungsverhalten der Coelomzellen von Psammechinus miliaris bei der Wundheilung (Echinodermata)
}

\author{
WILLI KUHL \\ Institut für Kinematische Zellforschung der JoHANN-WoLfGANG-GoETHE-Universität \\ in Frankfurt am Main \\ Biologische Anstalt Helgoland, Meeresstation, Helgoland
}

\begin{abstract}
The locomotory behaviour of coelom cells of Psammedbinus miliaris (Echinodermata) during wound-healing. In the sea urchin $P$. miliaris application of time lapse photography allows a study of the very slow movements of coelom cells during the healing process of small wounds on the surface of the calcareous skeleton near the periproct. For observation and time lapse photography LEITZ-Ultropak objectives were used (incident light). Ambulacral feet, spines and pedicellaria were removed, and the animal was fixed in three places in a ring of plexiglass by means of three little screws, which touched the equator of skeleton. The rate of time transformation was $1 / 240$ to $1 / 480$. The film reveals the behaviour of coelom cells, which move out the skeleton to the surface of the small experimental region. Within several hours the white "polished" surface is covered with hundreds of red-brown amoebocytes; only these are visible on the white lime-ground; they have no function in the healing process, which takes place below the surface of the "primäre Wundverschlur" and therefore cannot be observed. There are three main types of coelom cells: red-brown amoebocytes, "körnchenführende Zellen" (white amoebocytes) and leucocytes ("netzbildende" or "skelettbildende Zellen"); the flagellated cells may be neglected here. In order to be able to study the behavior of the three main types of coelom cells, the "primäre Wundverschluß", i. e. the total cell-covering of the wound, is removed and torn into microscopic fragments. These are studied (time lapse) under normal optical conditions (transmitted light). The slides show many "aggregates" of different sizes, single cells and little calcareous concrements torn off the skeleton. The aggregates, even the big ones, exhibit slow locomotion and change their positions considerably. If the distance of two aggregates becomes small enough, they fuse. In these cases a loose cell bridge between the two aggregates is formed. Sometimes no union occurs, although the distance is very small. Even big aggregates suddenly show considerable contractions if spreading has preceded. All movements and place changing of cell-aggregates are caused by contractions and dilatations of the plasmatic network which forms the cellular basis. Little wounds in the newly built "Wundverschluß" scratched with a lancet, heal within several hours. Time lapse shows passive movements of small calcareous fragments, which by chance sometimes enter the small wounds, where they help and accelerate the closing of the injury. The fragments are fixed on the edge of the wound by newly produced lime. Skeleton building coelom cells ("netzbildende Coelomzellen") come up in batches from the depth of the sea urchin's skeleton; each cell contains lime crystals.
\end{abstract}




\section{EINLEITUNG UND UNTERSUCHUNGSMETHODE}

Die Ergebnisse von Untersuchungen über das Bewegungsverhalten der Coelom-

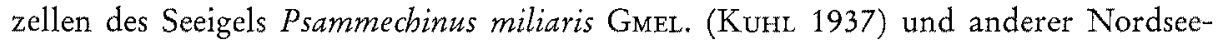
Echinodermen legten es nahe, deren Funktionen, möglichst in situ, am intakten Seeigel zu prüfen, also unter Vermeidung der Explantation der Zelletn. Für derartige Versuche kommt nur Auflichtbeleuchtung in Betracht; mit Vorteil wird die Ultropakeinrichtung (E. LEITZ) mit Immersionsansätzen an den Objekten verwandt. Mikro-Z.R.-Aufnahmen (Z.R.: Zeitraffung) ermöglichen die Darstellung der of sehr langsamen Bewegungsvorgänge.

Die Fortbewegung des Seeigels mit Hilfe der Ambulacralfüßchen muß völlig ausgeschaltet werden. Das Tier wird daher in einem Plexiglasring mittels dreier Plexiglasschräubchen, die mit ihren Spitzen nur in drei Punkten die Kalkschale berühren, festgehalten; es kann jedoch Ambulacralfüßchen, Stacheln und Pedicellarien ungestört bewegen und wird durch diese Art der Stillegung in keiner Weise geschädigt.

Der Plexiglasring mit dem Versuchstier wird an einem mit mehreren Kugelgelenken versehenen Halter befestigt, der außerdem eine Kreuzverschiebung trägt, welche die notwendige, sehr genaue Feineinstellung in zwei aufeinander senkrechten Richtungen in der Horizontalebene ermöglicht. Weiterhin ist eine Auf- und Abbewegung der gesamten Anordnung innerhalb weiter Grenzen vorgesehen. Der Plexiglasring mit dem Seeigel taucht in ein etwa $500 \mathrm{ccm}$ fassendes Gefäß, das mit Seewasser durchströmt werden kann. Zur späteren Kontrolle und erneuten Z.R.-Aufnahmen wird das Versuchstier im Plexiglasrahmen in das Hälterungsaquarium zurückgebracht und kann Nahrung aufnehmen.

Mikro-Z.R.-Aufnahmen auf der gekrümmten Skelettoberfläche des Seeigels sind bei Auflicht nicht möglich, weil diese mit Ambulacralfüßchen, großen und kleinen Stacheln sowie Pedicellarien - alle in ständiger Bewegung - dicht besetzt ist. Es wird daher ein wenige Quadratmillimeter umfassendes Areal von den störenden Anhängen befreit. Am besten eignet sich die Gegend in der Nähe des Periproct. Die kleine, glatte, gelblich-weiße Skelettzone kann mit Hilfe der Feinbewegung der Kreuzverschiebung unter den Immersionsansatz "gesteuert“ werden.

\section{BEWEGUNGSVERHALTEN DER ROTBRAUNEN AMOEBOCYTEN AN DER SKELETTOBERFLACHE}

Eine Mikro-Z.R.-Aufnahme der noch in situ befindlichen Zellelemente am Rande des Operationsfeldes enthüllt, daß die rotbraunen Amoebocyten auf der Seeigeloberfläche die gleiche Vitalität aufweisen wie die in der Coelomflüssigkeit; dies kann als ein Argument gegen die Auffassung dieses Typs als „Exkretionszellen“ angesehen werden (Gegenhypothese: „Atmungsfunktion“).

Die nur unter Z.R. sichtbar werdende Metabolie des Zellkörpers dieser Coelomzellen, welche den Farbstoff Echinochrom enthalten, ist sehr charakteristisch. Kurz nach der Entnahme von Coelomflüssigkeit werden alternierend nach allen Seiten rundliche Plasmaprotuberanzen gebildet, die sofort nach der Verwölbung eingezogen und 
wieder vorgestreckt werden; eine Ortsveränderung tritt zunächst nicht oder nur in geringem Umfang ein. Einige Stunden nach Herstellung des Präparates wird die Protuberanzenbildung eingestellt. Die rotbraunen Amoebocyten nehmen eine langgestreckte Gestalt an und beginnen langsam „fortzukriechen". Sie weisen jetzt ein verdicktes physiologisches „Vorderende" und ein verschmälertes „Hinterende“ auf. Die Ortsveränderung ist nicht geradlinig, sondern verläuft in unregelmäßigen Kurven. Die Z.R. läßt ferner erkennen, daß das „Vorderende "zum „Hinterende" werden kann: Die Zellen „kriechen“ sozusagen durch sich selbst „hindurch“. Das „neue Vorderende“ zeigt jetzt die typische breitrunde Gestalt. Dieser Vorgang kann sich in kurzen Intervallen wiederholen. Die rotbraunen Amoebocyten gleichen nummehr in Habitus und Bewegung den „körnchenführenden Zellen “, deren Funktion ebenfalls noch unbekannt ist.

Auf der Skelettoberfläche des Seeigels wurde bis jetzt nur der langgestreckte, zuletzt genannte Bewegungstyp der rotbraunen Amoebocyten unter Z.R. festgestellt.

\section{AUSWANDERN DER COELOMZELLEN AUS DEM KALKSKELETT}

Wird auf die glattgeschliffene, von Stacheln und Füßchen befreite kleine Operationsstelle scharf eingestellt, so ist dieses gelblich-weiße Feld völlig frei von Coelomzellen. Sehr bald „kriechen“ die ersten rotbraunen Amoebocyten aus den mikroskopisch kleinen, streng gesetzmäßig angeordneten Lücken der Skelettstruktur heraus;
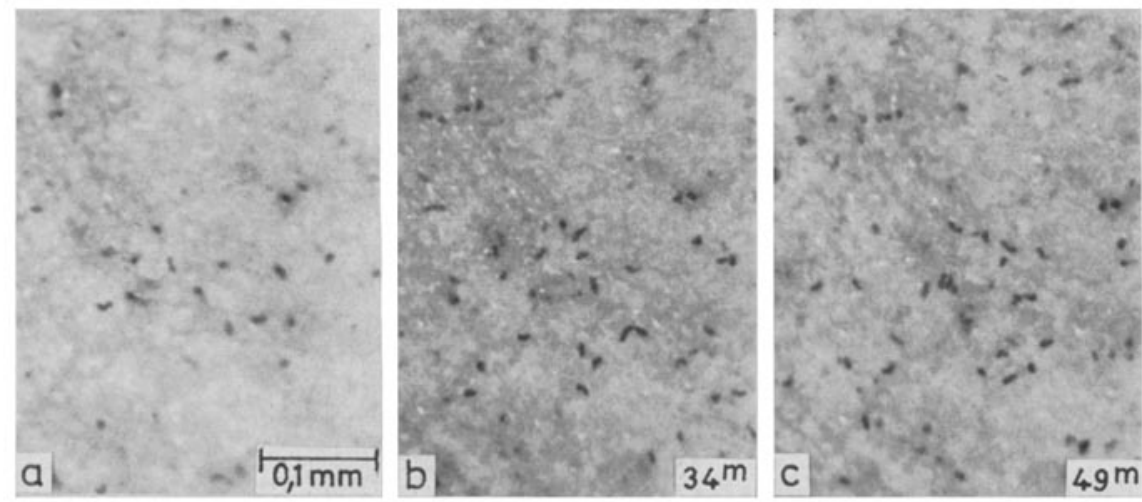

Abb. 1: Psammechinus miliaris. Von Stacheln und Ambulacralfüßchen befreites, glattes Operationsfeld in Periproctnähe. a: Beginn des Auswanderns der Amoebocyten aus dem Kalkskelett; auf dem hellen Untergrund sind nur die rotbraunen Amoebocyten im Auflicht erkennbar; b: die Anzahl der ausgewanderten rotbraunen Amoebocyten ist stark vermehrt; c: $15 \mathrm{Mi}$ nuten später; weitere Zunahme der Anzahl der Zellen. (Aus Zeitrafferfilm.)

unter Z.R. zeigen sie eine lebhafte Bewegung, die mit erheblicher Ortsveränderung verbunden ist (Abb. 1a und 2a). Die langgestreckte Gestalt in dieser Phase (siehe oben) und die Fähigkeit zu starker Metabolie (im alten Sinn: Veränderlichkeit der Gestalt) ermöglicht es diesen Zellen, sich durch die engen "Maschen" des Schalenskeletts hin-" 

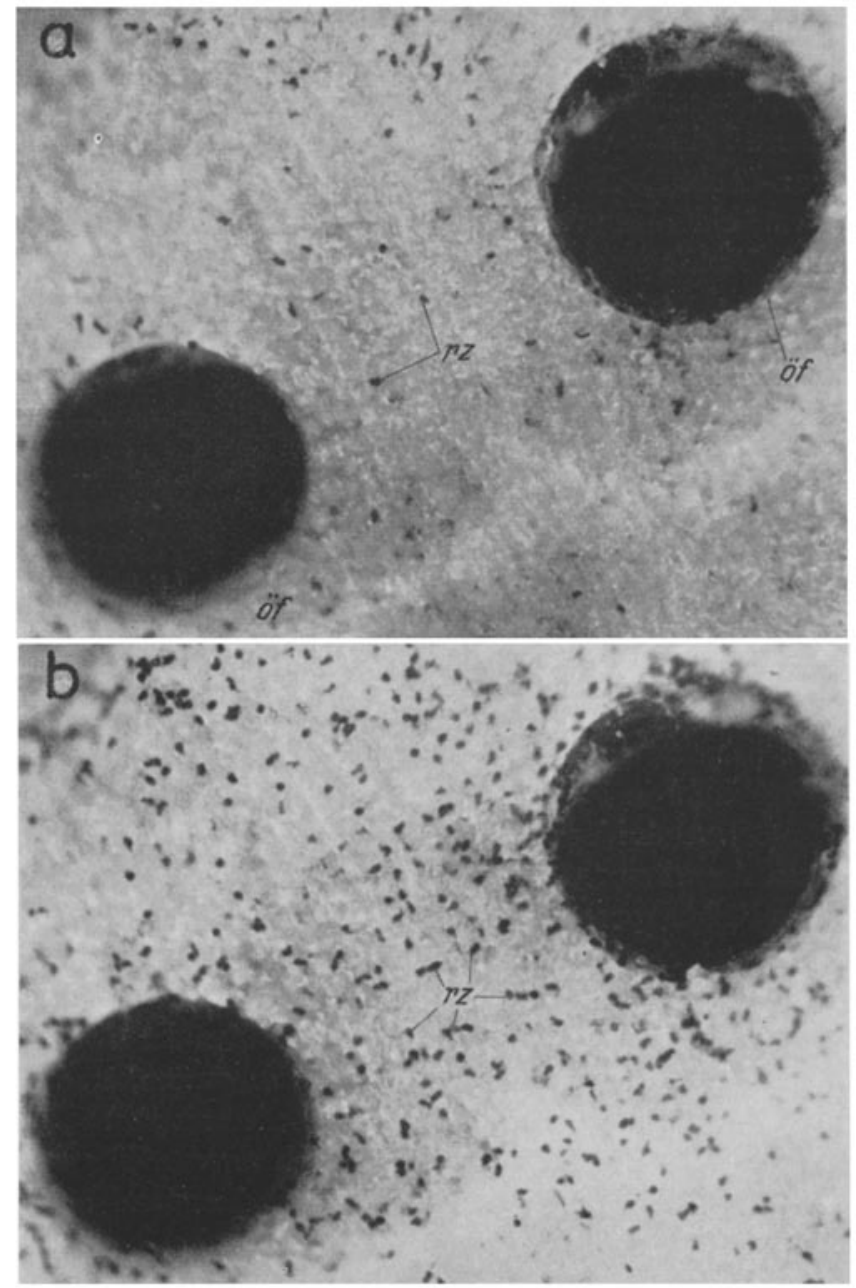

Abb. 2: P. miliaris. a: Zwei Füßchenporen auf abgeschliffenem kleinem Operationsfeld. Beginn des Auswanderns von rotbraunen Amoebocyten ( $r z$ ) aus dem Kalkskelett (öf: abgeschliffene Poren eines Ambulacralfüßchens); b: einige Stunden später; Anzahl der rotbraunen Amoebocyten stark vermehrt, farblose Amoebocyten auf dem hellen Untergrund nicht erkennbar. (2 Teilbilder aus Zeitrafferfilm; nach KuHL 1942.)

durch zu zwängen. Stärkere Vergrößerungen lassen im Z.R.-Laufbild erkennen, daß die rotbraunen Amoebocyten auch wieder unter dem oberflächlichen Bälkchenwerk des didken Schalenskeletts verschwinden können (Abb. 9a, d, e).

Dieser tiefdunkel erscheinende Zelltyp „bevölkert" allmählich die gesamte Operationsstelle (Abb. 1c und 2b). Die übrigen Zellelemente der Coelomflüssigkeit, die als netzbildende, farblose Amoebocyten, "körnchenführende Zellen" und Zellen mit "flaps" (= membranöse Pseudopodien) anzusprechen sind (KuHL 1937), verlassen ebenfalls das Bälkchenwerk der gewölbten Schale an der Wundstelle. Diese Zellen sind 
leider infolge ihrer Farblosigkeit auf dem hellen, gelblich-weißen Untergrund der abgeschliffenen Schalenregion im allein möglichen - ungewohnten - Auflicht überhaupt nicht zu erkennen, was sehr zu bedauern ist, weil sich unter diesen Coelomzellen gerade die befinden, denen bei der Wundheilung die Hauptaufgabe zufällt: Die netzbildenden Zellen (Abb. 5). Diese Tatsache ist bei den folgenden Ausführungen stets zu berücksichtigen. Leider lassen sich bei $P_{\text {sammechinus miliaris die farblosen Amoebo- }}$ cyten nicht durch Vitalfarbstoffe, etwa Neutralrot, anfärben und dadurch auf dem hellen Untergrund sichtbar machen, im Gegensatz zu Asterias rubens, der wiederum infolge der großen Beweglichkeit des Kalkskeletts für derartige Versuche unter Anderung des Zeitfaktors völlig ungeeignet ist.

Aus Abbildung 1a bis c erhellt die Zunahme der Anzahl der rotbraunen Amoebocyten im Verlauf von 49 Minuten; die langgestreckte "Wanderform“ dieses Zelltypus ist deutlich erkennbar. Man muß sich vorstellen, daß das ganze Versuchsfeld mit einem mehr oder weniger engmaschigen Plasmanetz überzogen ist, das ständig Gestalt und Maschenweite ändert und leider nur im Explantat im Durchlicht deutlich sichtbar zu machen ist (Abb. 5). Auf diesem lebenden, von den "netzbildenden Zellen" (KuHL 1937) hergestellten Plasma-Maschenwerk bewegen sich die übrigen Coelomzell-Typen (Abb. 5; Durchlicht, Explantat).

Abbildung 2 zeigt an zwei Teilbildern einer Ultropak-Z.R.-Aufnahme ein abgeschliffenes Versuchsfeld in Periproctnähe im Bereich der beiden Poren eines Ambulacralfüßchens (öf). Auch hier sind wieder nur die aus dem Kalkskelett ausgewanderten rotbraunen Amoebocyten im Auflicht zu erkennen. Am unteren und oberen Rande der rechten Füßchenpore in $\mathrm{b}$ ragen größere Kalkpartikel über den Porenrand. Die verschiedene Gestalt der rotbraunen Zellen ( $r z$ beweist ihre starke Metabolie.

Einige Stunden nach der Entfernung der Füßchen, Stacheln und Pedicellarien an der Operationsstelle ist eine derart große Zahl von Zellen der Coelomflüssigkeit aus dem nur oberflächlich leicht verletzten Schalenskelett ausgewandert, daß die Versuchsregion von einer dicken, rötlich gefärbten Zellmasse bedeckt ist: dem „primären Wundverschluß" (Abb. 8 und 9). Zwischen den Zellen liegen verschieden große Kalkpartikel, die vom Abschleifen oder Abkratzen der kleinen Versuchsregion herrühren. Bei direkter Beobachtung dieses Wundverschlusses, auch mit Ultropakobjektiven hoher Apertur, ist nicht einmal andeutungsweise eine Bewegung in dieser scheinbar regellosen Masse von Coelomzellen und Kalkteilchen feststellbar.

Unter Z.R. können die verwickelten Bewegungsvorgänge im primären Wundverschluß im Laufbild sichtbar gemacht werden. Es bietet sid. der bemerkenswerte Eindruck eines ständig hin- und herwogenden "Zell-Kalk-Breies". Bereits nach 6 bis 7 Stunden erscheint das Versuchsfeld völlig geglättet. Die „Maschen“ des Bälkchenwerks des Skeletts sind nur noch andeutungsweise unter der Oberfläche der "neu eingebauten " Kalkelemente erkennbar.

Abb. 3: P. miliaris. 8 Teilbilder aus Zeitrafferfilm. Vereinigung von durch Zerzupfen des "primären Wundverschlusses" erhaltenen Aggregaten von Coelomzellen (aus dem Kalkskelett aktiv an die $W$ undoberfläche gewandert). Zwischen den Teilbildern d und e liegt ein Zeitintervall von $4 \mathrm{~h} 48 \mathrm{~m}$. Wahrend der Versuchsdauer von $7 \mathrm{~h} 12 \mathrm{~m}$ wird die Anzahl der Aggregate von 14 auf 7 infolge von aktiven Vereinigungen reduziert. Alter des Wundverschlusses zu Versuchsbeginn: Drei Tage und 18 Stunden 

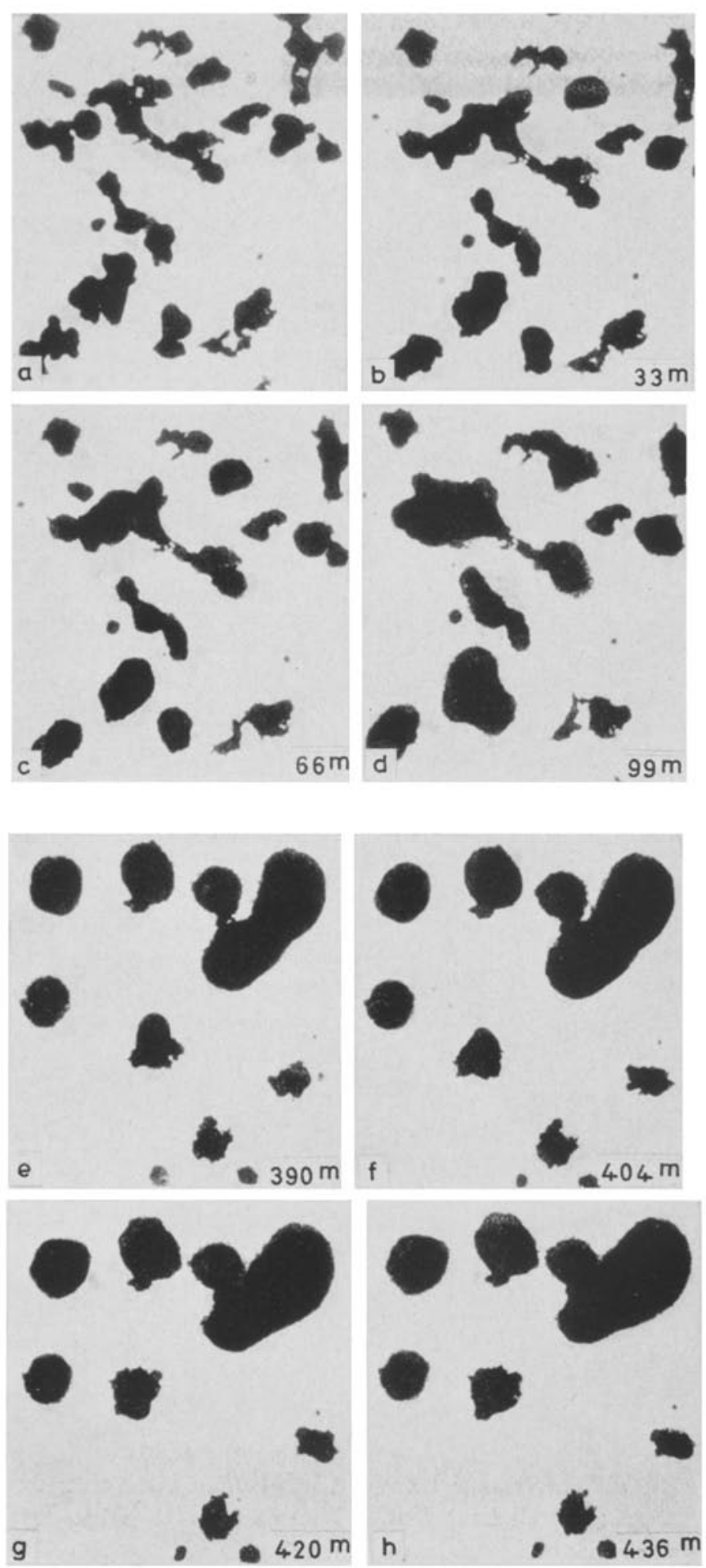
Da sich die eigentlichen Wundheilungsvorgänge, das heißst die Glättung der beschädigten Oberfläche des Kalkskeletts sowie die Neuausbildung der zerstörten Feinstruktur auf der Operationsfläche, unter dem „primären Wundverschluß" abspielen, lassen sich diese Prozesse leider nicht ohne weiteres unter Z.R. untersuchen und sichtbar machen. Es sei nochmals darauf hingewiesen, daß die Coelomzellen, welche für den Wundverschluß verantwortlich sind, aus den „Maschen“ des Skeletts der Seeigelschale durch aktive Bewegung auf die Schalenoberseite gelangen. Daraus läßt sich die Bildungsstätte der Coelomzellen im mesodermalen Kalkskelett erschließen. Dies stimmt überein mit den Ergebnissen von SCHINKE (1948), die mit Hilfe histologischer Methoden gewonnen wurden. Normalerweise erfolgt der Ersatz der Coelomzellen in der Coelomflüssigkeit durch Auswandern der Zellen aus dem Kalkskelett der Schale unter Durchbrechung des Coelomepithels (SCHINKE).

\section{„PRIMARER WUNDVERSCHLUSS“ UND DAS VERHALTEN EXPLANTIERTER AGGREGATE VON COELOMZELLEN}

Auf folgendem Umweg können die Verhaltensweisen der den primären Wundverschluß bildenden Coelomzellen und Zellagregate einer Untersuchung zugängig gemacht werden: Die Zell-Kalk-Masse wird vorsichtig, möglichst in toto, von der Operationsstelle abgenommen, mit zwei feinen Nadeln zerzupt und in der Mikrokammer in Seewasser im durchfallenden Licht unter Z.R. untersucht (Abb. 3 und 4).

Im zerzupften Wundverschluß (Abb. 3a) erkennt man Einzelzellen aus der Coelomflüssigkeit, wenigzellige, mittlere und größere Zellaggregate. Die mittleren und großen Aggregate sind völlig undurchsichtig bis auf ihre schmale Randzone. Einzelzellen und kleine Aggregate zeigen unter Z.R. lebhafte Bewegung; die wenigzelligen Aggregate vereinigen sich meist, sobald ihre Ortsänderung die Abstände $\mathrm{z}$ wischen ihnen verringert hat.

Unmittelbar nach dem Zerzupfen des primären Wundverschlusses und der Explantation der entstandenen Aggregate in ein Mikroaquarium (Anwendung der Universaltauchkappe; KuHL 1954) liegen im Versuch der Abbildung 3a anfänglich 14 verschieden große Aggregate vor, die im Zeitraum von 99 Minuten infolge von Vereinigungen auf 11 meist abgerundete "Coelomzellverbände" reduziert werden (Teilbild d). Nach einer Pause von $4^{\mathrm{h}} 48^{\mathrm{m}}$ ( ${ }^{\mathrm{h}}$ : Stunden, $\mathrm{m}$ : Minuten) ist die Anzahl der größeren Aggregate weiterhin auf 7 zurïckgegangen (Abb. 3e); diese Zahl bleibt bis zum Versuchsende bestehen (Abb. $3 \mathrm{~h}$ ).

Auch die mittelgroßen Aggregate können Ortsverlagerungen aufweisen, die sie in die Nachbarschaft anderer Aggregate und zur Vereinigung mit diesen führen. Infolge ihrer Dicke ist nur die lebhafte Bewegung der randlichen Amoebocyten zu erkennen. Häufig zeigen diese Aggregate unter Z.R. plötzlich eine Kontraktionsbewegung, wodurch die Gesamtgröße des Aggregates oft auf die Hälfte reduziert werden kann. Der Kontraktion geht meist eine mehr oder weniger starke Ausbreitung und flächenhafte Vergrößerung der Zellansammlung voraus. Diese kommt infolge der Ausbildung und Ausbreitung der (nicht sichtbaren) Plasma-Netze zustande, die an der Unterlage in verschiedenem Grade festhaften und die lebene „Basis" des Aggregats bilden. 

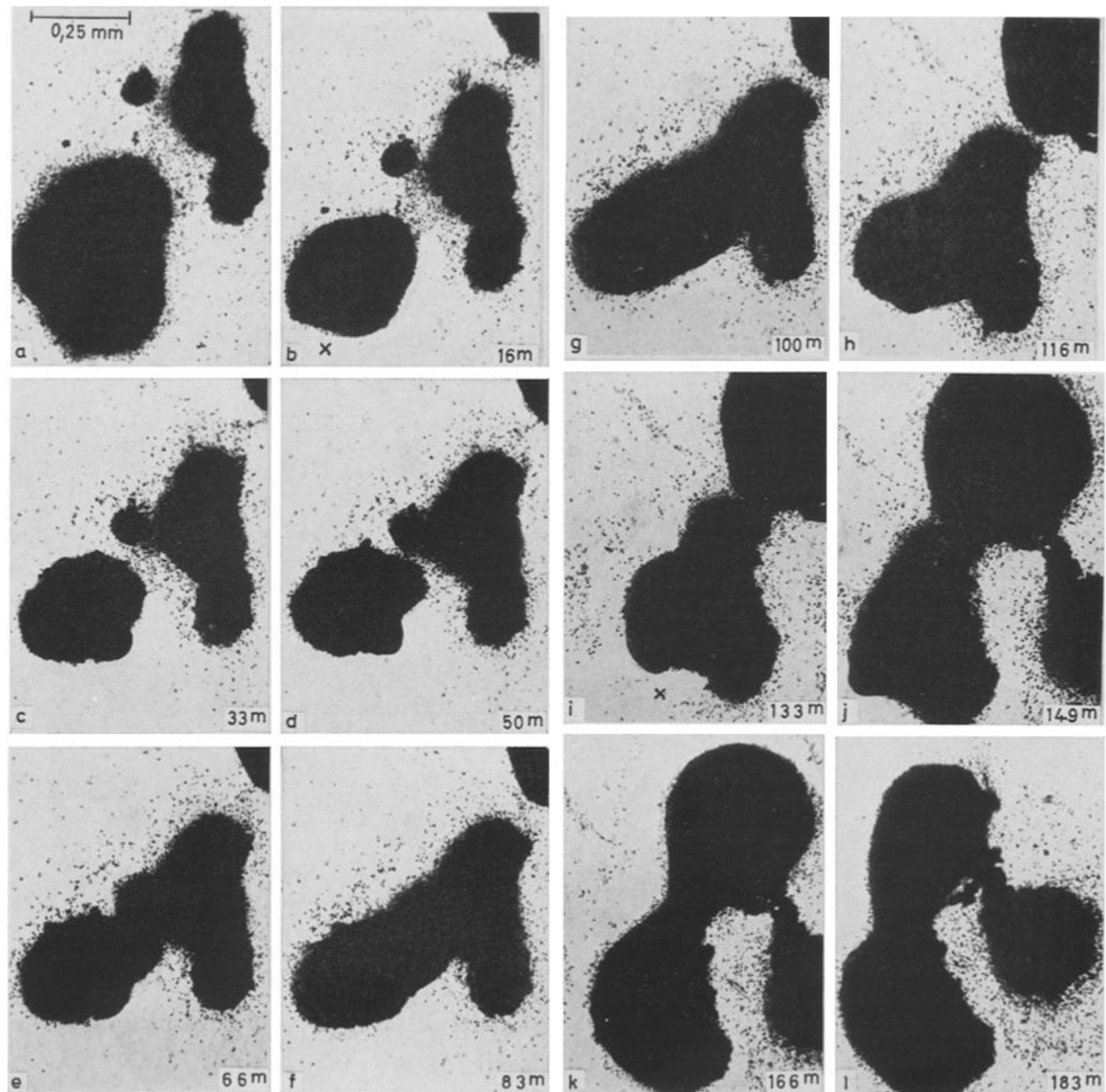

Abb. 4: P. miliaris. Das Bewegungsverhalten von drei mittelgroßen Aggregaten von Coelomzellen aus dem in Abbildung 3 dargestellten Versud. Zahlreiche rotbraune Amoebocyten in den Randzonen der Aggregate erkennbar; 12 Teilbilder aus Zeitrafferfilm; sie umfassen einen Zeitraum von $3^{\mathrm{h}} 3^{\mathrm{m}}$; b: das große Aggregat hat sich stark kontrahiert; $\mathrm{c}$ : noch stärkere Kontraktion, viele rotbraune Amoebocyten zwischen den beiden großen Aggregaten; d: beide große Aggregate in Kontakt; e: Vereinigung; $f$ bis g: Gestalt-Ausgleich; h: Kontraktion, groBes Aggregat nähert sich von rechts oben; i: Vereinigung mit diesem; $j$ bis 1 : Vereinigung mit viertem Aggregat, zunächst mit schmaler Zellbrücke; starke Auswanderung von rotbraunen Amoebocyten aus diesem von rechts schnell vorwandernden Aggregat 
In Abbildungen 4b und $\mathrm{i}$ ist eine derartige starke Kontraktion ( $\mathrm{x}$ ) zu erkennen. Der Aggregat-Vereinigung geht oft eine lebhafte Auswanderung der Coelomzellen voraus (Abb. 4b, c, d). Häufig werden vor der Vereinigung von Aggregaten aus dem Wundverschluß zuerst schmale „Verbindungen" hergestellt, wie zum Beispiel in Abbildung $4 j, k, 1$. Es können sich auch Aggregate mit Hilfe der nicht sichtbaren plasmatischen Netze dicht aneinander vorbeibewegen, ohne daß es zu einer Vereinigung kommt.

Aus früheren Untersuchungen über das Bewegungsverhalten der Coelomzellen der Echiniden geht hervor, daß die Plasmanetze sich kontrahieren und dilatieren können. Diese Fähigkeit gibt den Schlüssel zum Verständnis des Verhaltens der aus dem primären Wundverschluß mechanisch isolierten Aggregate. Bei der Ausbreitung eines Aggregates mittlerer Größe, die einer Kontraktion vorausgeht, erkennt man deutlich die mehr oder weniger radiär ausstrahlenden Netze, welche mannigfaltig gestaltete Quer- und Schrägverbindungen aufweisen. Bei der Zusammenziehung wird die „Maschenweite" erheblich verringert; die aufgelagerten verschiedenen Zelltypen der Coelomflüssigkeit werden „zentripetal" mitgerissen, wodurch die erhebliche Verkleinerung des Aggregats verständlich wird, dessen Zellenzahl ja, abgesehen von den randlichen, ausgewanderten Zellen, im wesentlichen die gleiche bleibt (Abb. 3a, b).

Nähern sich Aggregate mittlerer Größe, so erfolgt keineswegs in allen Fällen eine Vereinigung; es kommt vor, daß sich das eine Aggregat kurz vor der Berïhrung mit einem anderen plötzlich (Z.R.) stark zusammenzieht und dadurch den Abstand wieder erheblich erweitert. Es ist zunächst noch nicht möglich, dieses Verhalten zu deuten.

Die basalen Plasmanetze der Aggregate weisen lebhaftere Gestaltänderungen auf als die randlichen Netzbildungen, die über das Aggregat hinausragen (Abb. 5; Teilbilder a bis j). Die "Maschen" des lebenden Netzwerkes der Randzone eines explantierten Wundverschlusses im durchfallenden Licht (Abb. 5) sind verschieden groß; sie wechseln dauernd langsam ihre Gestalt. Es kommt vor, daß in den "Maschen“ andere Coelomzellen eingeschlossen werden. Abbildung $5 \mathrm{a}$ (hier $\mathrm{x}$ ) bis g zeigt die über $30 \mathrm{Mi}$ nuten währenden „Befreiungsversuche" eines eingeschlossenen rotbraunen Amoebocyten, bis die ihn umschließende "Masche" zufällig geöffnet wird $(\mathrm{g}, \mathrm{h})$. Eine Teilbildanalyse der komplizierten Verformungen der plasmatischen Netze stößt auf große technische Schwierigkeiten.

In den Teilbildern a bis $\mathrm{j}$ der Abbildung 5 zeigt das randliche Plasmanetz die Tendenz, sich auf das zugehörige Aggregat (am unteren Bildrand sichtbar) langsam zurïckzuziehen. Dabei bilden die dünnen "Maschenwände“ der Netze (a,b) allmählich unregelmäßig gestaltete „Plasmainseln“ $(i, j)$. Ob und inwieweit andere Coleomzellen an der Gesamtbewegung der explantierten Aggregate beteiligt sind, läßt sich kaum feststellen.

Im zerstückelten primären Wundverschluß finden sich auch zahlreiche Kalkpartikel verschiedener Größe, die bei der Glättung des Versuchsfeldes aus ihrem Verband in den oberen Schichten des Kalkskeletts herausgerissen wurden und meist die mehrfache Größe eines Amoebocyten aufweisen. Diese Kalkstückchen werden ebenfalls passiv durch direkte Berührung mit den Amoebocyten oder durch Kontakt mit den plasmatischen Netzsträngen hin- und herbewegt. Relativ große Kalkteilchen können passiv auf den Netzen weitgehend verlagert werden. Ohne genaue Kenntnis des Bewegungs- 

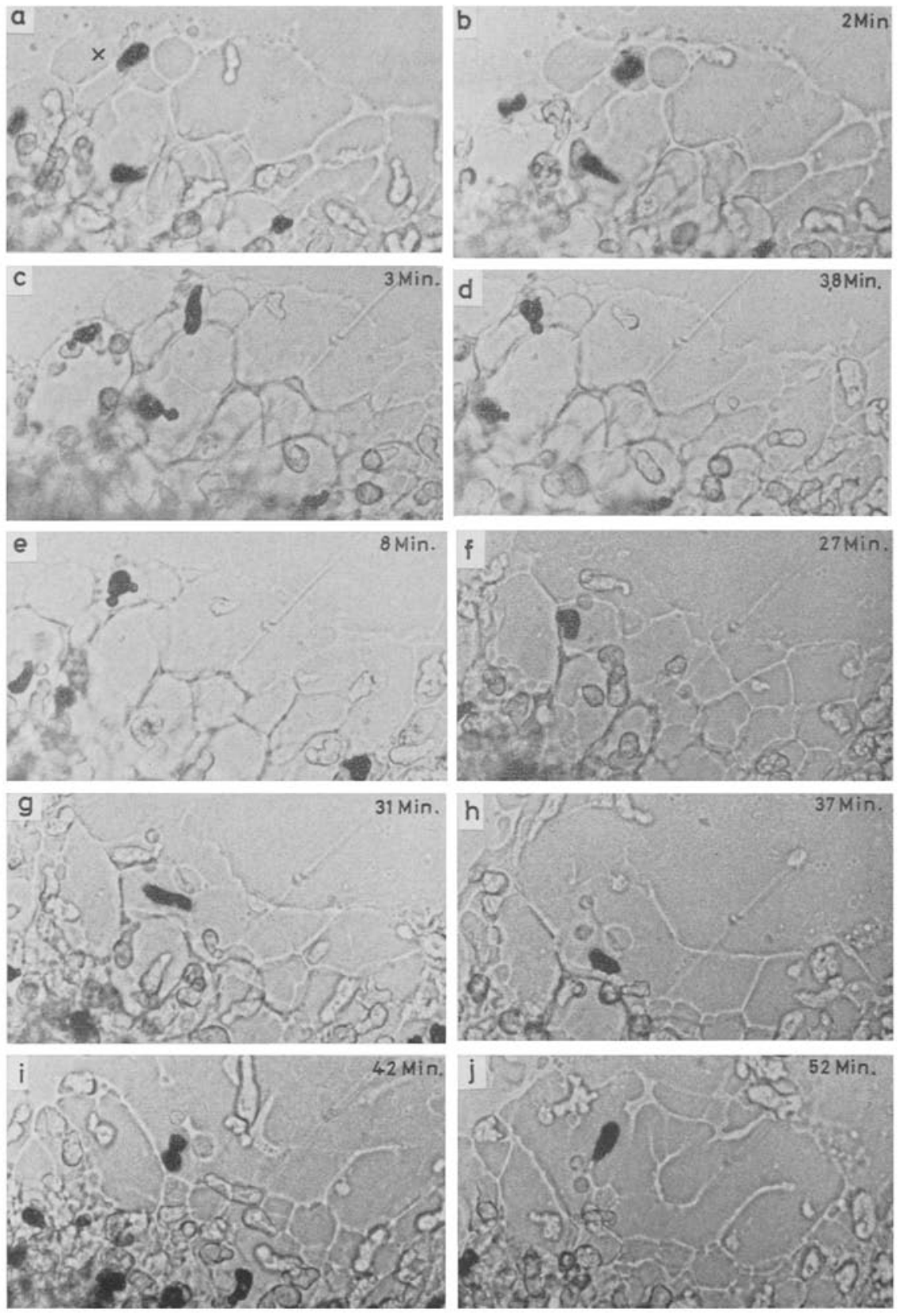

Abb. 5: P. miliaris. 10 Teilbilder der Randzone eines explantierten Aggregates aus zerzuptem primärem Wundverschluß. Stark veränderliches plasmatisches Netzwerk der randlichen, netzbildenden Zellen. a bis $\mathrm{f}$ : der in a mit $X$ bezeichnete rotbraune Amoebocyt ist in einer Plasma- "Masche" des Netzwerkes fast eine halbe Stunde eingeschlossen; g: infolge Zurückweichens des Plasmanetzes wird die "Masche" geöffnet, die Zelle wird frei: Bei der proximaden Rückbewegung des plasmatischen Netzes verschmelzen die Netzstränge oft zu „PlasmaInseln" ( $i$ und $j)$ 
verhaltens der netzbildenden Coelomzellen und der verwickelten lebenden plasmatischen Netzstrukturen, ihrer Fähigkeit, dauernd „Maschenform " und „Maschenweite“ zu verändern, lassen sich die bemerkenswerten Bewegungsvorgänge im Auflicht-Z.R.Film überhaupt nicht verstehen. Da die feinen Netzstrukturen auf dem hellen Untergrund auch nicht andeutungsweise zu erkennen sind, können daher nur die Folgeerscheinungen der langsamen Kontraktionsvorgänge untersucht werden.

Mittlere und große Amoebocyten-Aggregate haben die Fähigkeit, ihre abgeflachtrundliche Gestalt nach weiteren künstlich gesetzten Verletzungen, zum Beispiel durch randliche, tiefe Einschnitte, rasch wieder herzustellen. Die Schnittwunde schließt sich
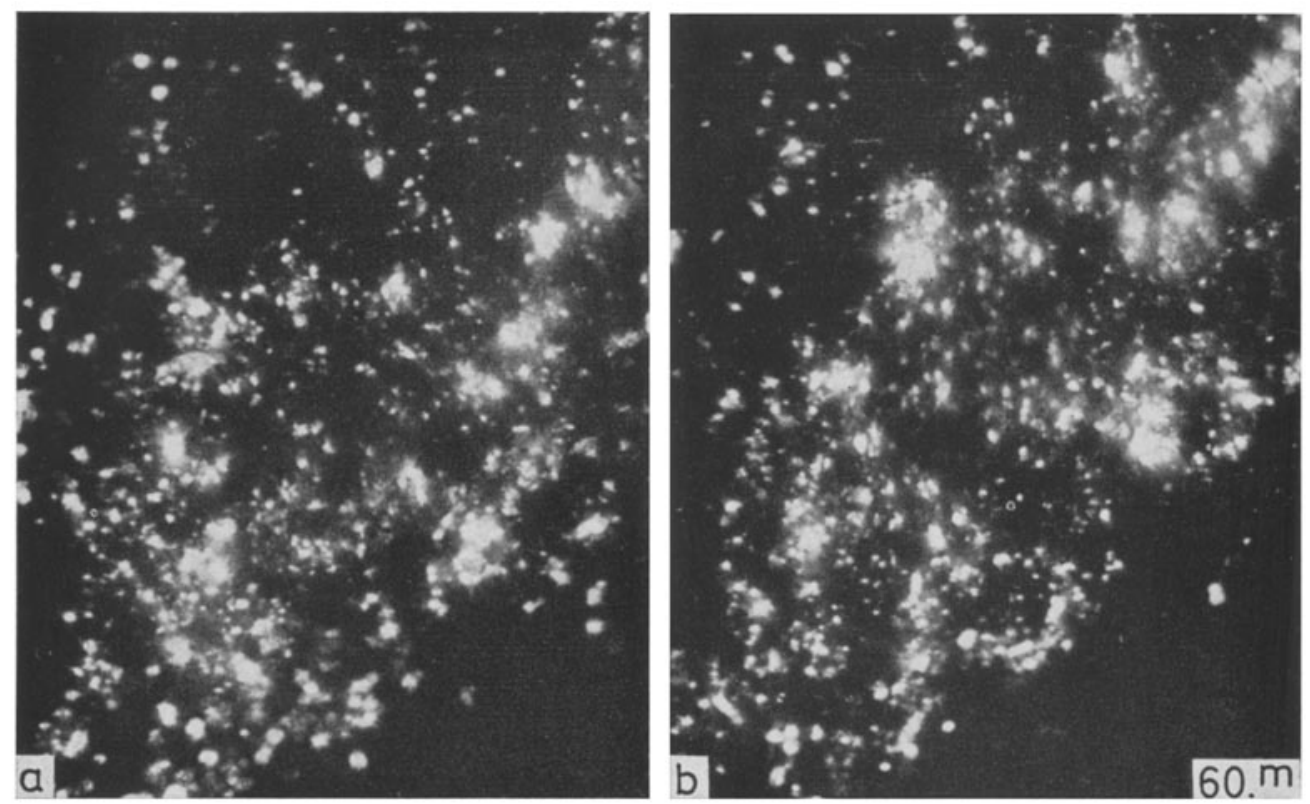

Abb. 6: $P$, miliaris. Teil eines durch Zerzupfen des primären Wundverschlusses erhaltenen Aggregates im durchfallenden polarisierten Licht bei gekreuzten Nicols. Intensives Aufleuchten der doppelbrechenden, verschieden großen Kalkkristalle in den skelettbildenden Zellen, die selbst nicht zu erkennen sind. Unter Z.R. zeigten die Ortsveränderungen der Kristalle die Bewegungen der Zellen an; b: die Lage eine Stunde nach a (aus Zeitrafferfilm)

langsam infolge des Vorwanderns von Amoebocyten von innen nach außen; dabei kann der Rand des distad sich verschiebenden Zellmaterials völlig glatt werden. Dies kann wohl nur dadurch eintreten, daß die Zellfortsätze der in Richtung auf die Peripherie des Aggregats sich vorschiebenden Amoebocyten temporär miteinander vereinigt werden und somit einen für den raschen Verschluß des Einschnitts günstigen tangentialen Plasmastrang bilden. Die Undurchsichtigkeit der größeren Aggregate verhindert eine Untersuchung dieses Vorgangs im einzelnen am lebenden Zellmaterial.

Der isolierte primäre Wundverschluß erlaubt ferner die Beobachtung der herausgerissenen größeren und der mikroskopisch kleinen, neu in den skelettbildenden Zellen entstandenen Kalkkristalle im polarisierten Licht. Bereits bei nur wenig gekreuzten 
Polarisationsfolien leuchten die doppelbrechenden Kalkelemente hell auf. Unter Z.R. wird ihre passive Ortsverlagerung in sehr instruktiver Weise deutlich. Die noch in den Zellen liegenden Kristalle werden als helle Lichtpunkte sichtbar. Bei einer derartigen Einstellung sind die Zellgrenzen und die aktiven Bewegungen der Amoebocyten mit den Kalkkristallen gerade noch deutlich wahrnehmbar. Bei völlig gekreuzten Polarisationsfolien oder Nicols sieht man im Z.R.-Laufbild lediglich das sehr eindrucksvolle Hin- und Herwogen der hellaufleuchtenden größeren und kleineren Kalkkristalle, entsprechend den Bewegungen der sie erzeugenden Zellen.

Abbildung 6 zeigt zwei Teilbilder aus einer derartigen Z.R.-Aufnahme eines zerzupften und explantierten Aggregats des primären Wundverschlusses im durchfallenden Licht bei gekreuzten Nicols. Die kleinsten, hell aufleuchtenden Partikel sind die ersten Kristallbildungen innerhalb einer skelettbildenden Zelle. Abbildung $6 \mathrm{~b}$ läßt die erheblichen Verlagerungen der Kristallelemente nach einer Stunde erkennen.

Die Ergebnisse der Z.R.-Filmauswertung des mehr oder weniger stark zerzuptten und explantierten primären Wundverschlusses ermöglichen durch die Klarstellung der "Potenzen“ dieser aus dem Kalkpanzer stammenden Zellanhäufungen das Verständnis für die langsamen Bewegungen der Zellelemente während der Wundheilung in situ auf der Operationsstelle im Auflicht (Ultropak). Trotz der bereits erwähnten Erschwerung der Deutung der Bewegungsphänomene infolge der Tatsache, daß sich nur die rotbraunen Amoebocyten deutlich vom hellen Kalkhintergrund abheben (Abb. 1 und 2), denen bei der Wundheilung keine Funktion zukommt, ist es jetzt möglich, die wichtige Funktion der netzbildenden Amoebocyten (= "Leucocyten") wenigstens in ihrer Auswirkung zu verstehen.

\section{VERSCHLUSS KLEINER „KRATZER“ IM PRIMAREN WUNDVERSCHLUSS}

Wie oben dargelegt, zeigt der primäre Wundverschluß wenige Stunden nach dem Abschaben der Operationsstelle unter Z.R. eine anscheinend ungeregelte, "wogende Bewegung" der Zellaggregate und Kalkpartikel. Für eine Untersuchung der hier auftretenden sehr langsamen Bewegungsvorgänge ist diese sehr dicke "Zell-Kalkmasse" ungeeignet. Es wurde daher folgende Versuchsanordnung angewandt: Nach Vorbereitung der Operationsstelle wird abgewartet, bis eine mehr oder weniger dichte "Zellbevölkerung" der glatten Wundfläche eingetreten ist. Mit einer geeignet zugeschliffenen Lanzettnadel werden feine Kratzer in den Zellüberzug gesetzt, deren Verlauf und Tiefe variiert wird. Durch verschiedene Nadelformen und eine Veränderung der Neigung zur Skelettoberfläche während der Nadelführung lassen sich die kleinen Verletzungen in ihrer Mikrostruktur weitgehend variieren. Die Z.R.-Aufnahme setzt sofort nach diesem kleinen Eingriff ein.

Der durch die Nadel verursachte kleine Graben in der Skelettoberfläche hebt sich hell vom dunkleren Untergrund der Zellmassen des Wundverschlusses ab. Im Gegensatz dazu sind die Ränder des Kratzers durch unregelmäßig angeordnete gelblich-weiße Kalkanhäufungen gekennzeichnet, die durch die Nadel aus dem Gitterwerk der Seeigelschale herausgerissen wurden (Abb. 7 und 8). Im Z.R.-Laufbild werden nun die am 


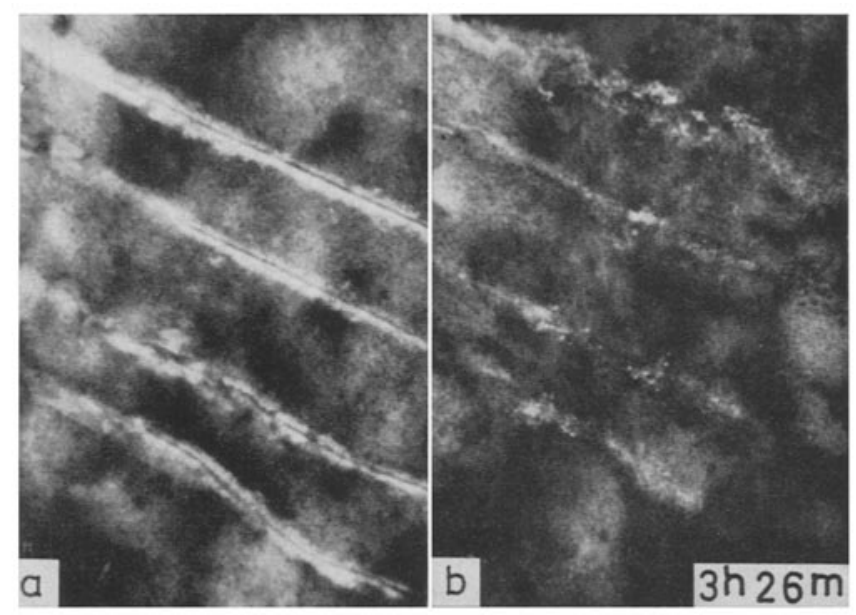

Abb. 7: P. miliaris. Vier feine "Kratzer" im primären Wundverschluß. a: sofort nach Setzen der Kratzer; b: 3h $26 \mathrm{~m}$ später. Die vier kleinen Verletzungen sind nahezu mit „altem" Kalkmaterial ausgefüllt

isolierten Wundverschluß im durchfallenden Licht festgestellten Bewegungsvorgänge in den durch Anwendung der Ultropak-Auflichtbeleuchtung gegebenen Möglichkeiten erkennbar: Es können nur die rotbraunen Amoebocyten deutlich sichtbar werden, denen bei der Wundheilung keine Bedeutung zukommt. Sämtliche eindrucksvollen passiven Verlagerungen der herausgekratzten losen Kalkpartikel erfolgen auch hier auf Grund von Kontraktionen und Dilatationen der flächenhaft weitausgedehnten plasmatischen Netze der netzbildenden Amoebocyten.

Führt man die Lanzettnadel schräg zur Oberfläche des Kalkskelettes, so wird die eine Kante des „Mikrokratzers" unterhöhlt; es entsteht eine ausgeprägt scharfe Kante, die frei über den dunklen "Graben" ragt. Bei derartigen kleinen Verletzungen werden im Z.R.-Laufbild auch die "körnchenführenden Zellen" (= "weiße Amoebocyten") gerade als weißlich-opake, stark metabole Gebilde deutlich, und zwar nur in dem Augenblick, in dem sie über den scharfen Rand des unterhöhlten Kratzers „kriechen". Sobald sie den tiefdunklen Hintergrund des Grabens verlassen haben, werden sie auf dem hellen Untergrund, der sich an den Grabenrand anschließt, sofort wieder unsichtbar.

Bei dem verwirrenden Ausmaß der bemerkenswerten Bewegungsvorgänge im Bereich der Wundfläche ist es schwer zu entscheiden, ob die rotbraunen und "weißen Amoebocyten" bei der Verlagerung der losen größeren Kalkpartikel ebenfalls beteiligt sind. Auf Grund der Vorversuche am isolierten Wundverschluß in vitro ist dies wohl zu verneinen. Die ihrer Herkunft und Funktion nach unsicheren "Geißelzellen“ konnten im Auflicht nicht ermittelt werden; sie sind in diesem Zusammenhang auch ohne Interesse.

Abbildung 7 a zeigt vier frisch mit der Lanzettnadel gesetzte kleine Wunden auf einem 5 Tage vorher abgeschliffenen Versuchsfeld. Unter Z.R. werden folgende Bewegungsvorgänge im Laufbild sichtbar: (1) Lebhafte, offenbar regellos verlaufende Bewegungen der rotbraunen Amoebocyten (für die Heilungsvorgänge belanglos); sie fal- 

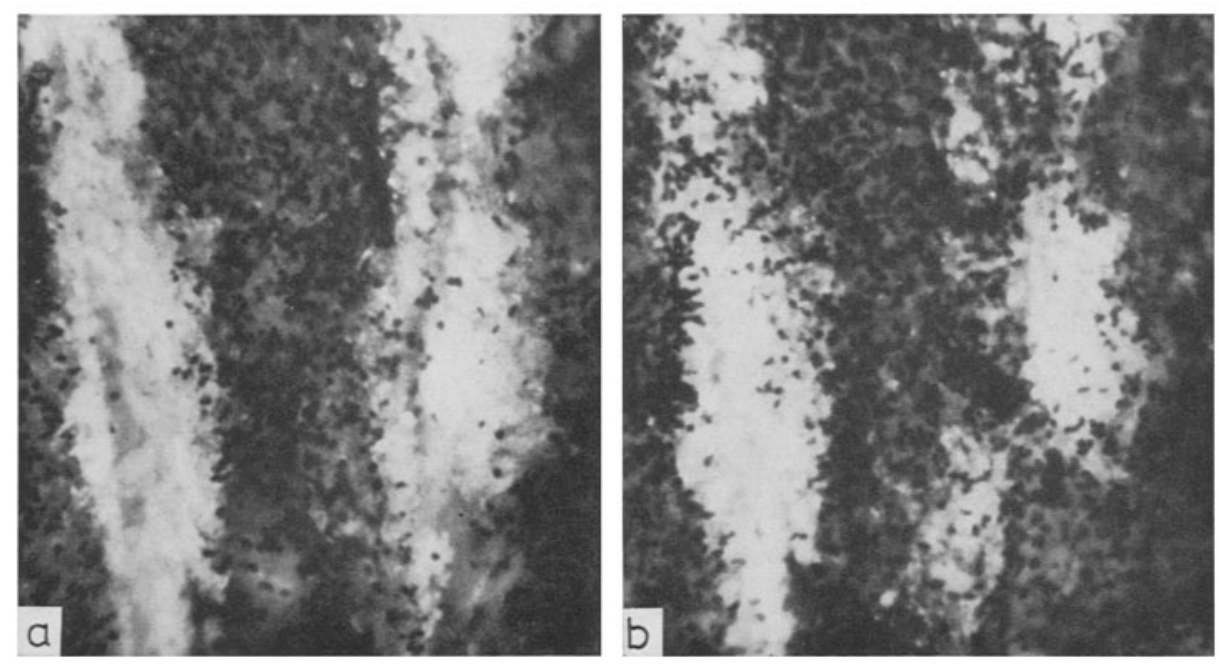

Abb. 8: P. miliaris. a: Zwei frisch gesetzte Kratzer, dicht nebeneinander. An den Wundrändern Anhäufungen von größeren mit der Nadel herausbeförderten Kalkpartikeln; b: im linken Kratzer ist eine, im rechten sind zwei "Brücken" gebildet, die aus Coelomzellen und Kalkmaterial, das herausgeschabt wurde, bestehen

len infolge ihrer Intensität besonders auf. (2) Verlagerungen von Kalkpartikeln außerhalb der Kratzer, an ihren Rändern und in der Tiefe des Risses selbst. Es kann der falsche Eindruck erweckt werden, als ob diese mehr oder weniger großen Kalkteilchen von den "lebhaften" rotbraunen Amoebocyten passiv bewegt würden. Die Analyse des Zellverhaltens im durchfallenden Licht zeigt jedoch, daß diese Verlagerungen nur infolge von Kontraktionen und Dilatationen der stark metabolen plasmatischen Netze zustande kommen. Es ist schwierig, anhand des Z.R.--Laufbildes Klarheit über die mannigfaltigen Verlagerungen der durch die Operationsnadel herausgerissenen Teile des Kalkskelettes zu gewinnen; die Teilbildanalyse kann leider infolge der unregelmäßigen Gestalt der Kalkpartikel nicht in exakter Weise angewandt werden.

Außerhalb des Kratzers liegen die größten aus dem Skelett herausgerissenen Kalkteilchen. Erst bei einer Z.R. auf $1 / 240$ bis $1 / 480$ werden ihre passiven Verlagerungen sichtbar, die in verschiedenen Richtungen auf die kleine Wunde, of parallel zu den Rändern, häufig auf der Stelle aber auch in die eingeritzte Furche hinein erfolgen. Meist bleiben Kalkteilchen an den Wundrändern haften; offenbar werden sie hier „eingebaut", das heißt mit den unverletzten Wundrändern durch Neubildung von Kalksubstanz vereinigt. Liegen solche Stellen einander gegenüber, so wird der Kratzer-Hohlraum schließlich ïberbrückt und geschlossen. Dies kann nach einigen Stunden an nahe benachbarten Stellen der Wunde stattfinden, indem durch Kalktrümmer gebildete, zunächst lockere, schmale „Brücken" die künstlich gesetzte Rinne im Skelett allmählich zugedeckt wird (Abb. 8b).

Setzt dann die im Ultropak-Auflicht leider nicht zu beobachtende "Verlötung“ dieses Kalkmaterials durch die Tätigkeit der unterdessen aus dem intakt gebliebenen Skelett herausgewanderten kalkbildenden Zellen ein, so hört jede weitere passive Be- 

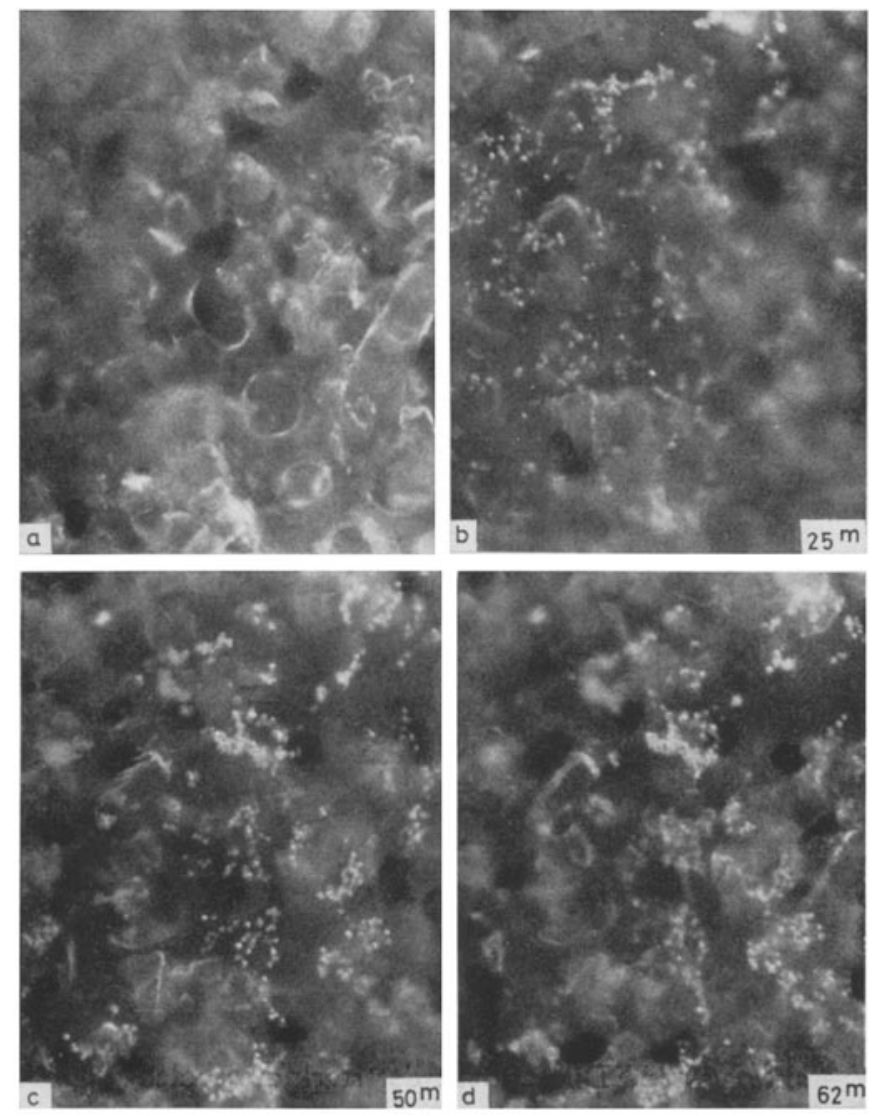

wegung auf; selbst im stark gerafften Z.R.-Laufbild herrscht in den überbrückten Teilen des Kratzers Ruhe.

Relativ häufig läßt der Mikro-Z.R.-Film erkennen, daß auch aus der Tiefe der Wundrinne bei der Verletzung losgerissene Kalktrümmer infolge der Tätigkeit der netzbildenden Coelomzellen an die Ränder der Wunde verlagert werden. Sie können auch in der Rinne hin- und herbewegt werden, bis sie ebenfalls endlich zum "Einbau“ kommen und keine passive Bewegung mehr aufweisen.

Der Einwand, Strömungen in der Seewasserküvette könnten diese passiven Ortsverlagerungen herausgerissener kleiner Skelett-Trümmer bewirken, wird dadurch hinfällig, daß einmal diese Bewegungen sehr langsam ablaufen und erst bei starker Z.R. im Laufbild sichtbar werden, zum anderen durch die Tatsache, daß bei der angewandten erheblichen Anderung des Zeitfaktors dicht nebeneinander liegende Kalkpartikel häufig eine entgegengesetzte Bewegung erkennen lassen. Es kommt auch vor, daß kleinere Kalktrümmer, die mehr oder weniger entfernt vom Wundrand liegen, an die Kante des Kratzers passiv verlagert werden und zum „Einbau“ kommen; jedoch wird auch das Gegenteil beobachtet. 

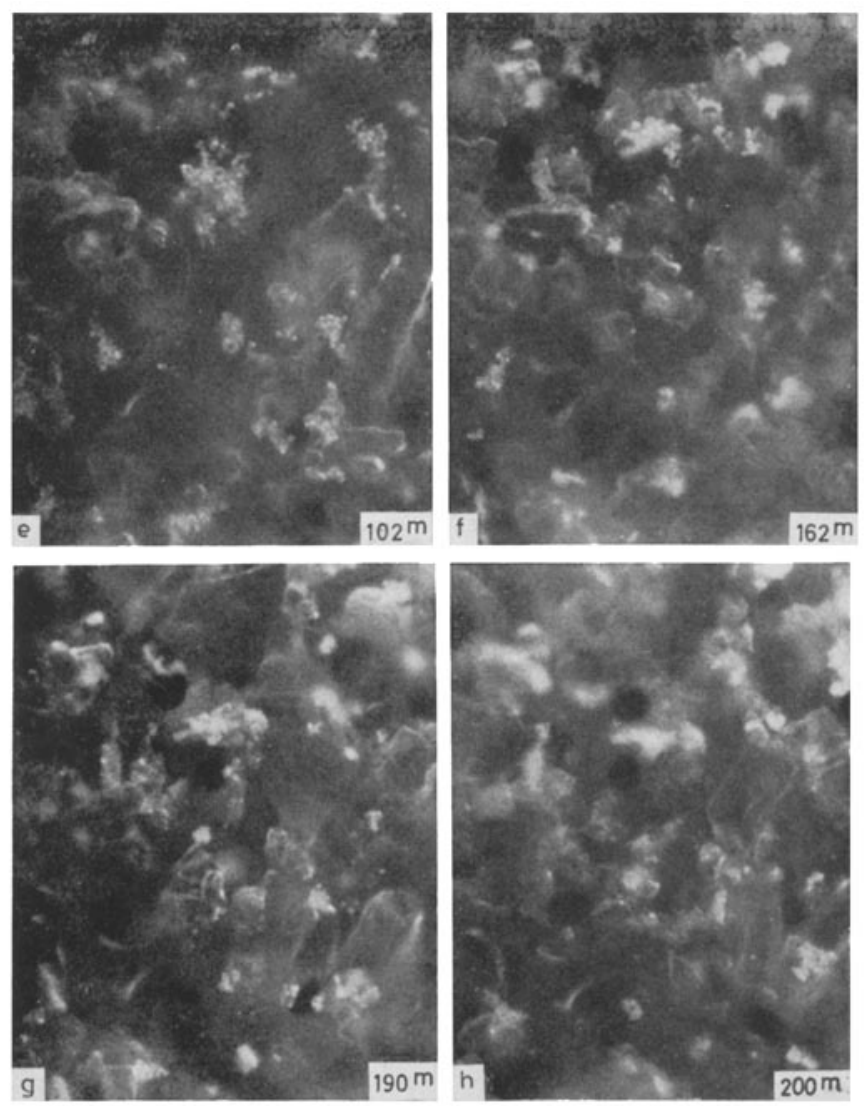

Abb. 9: P. miliaris. Acht Teilbilder aus einer Z.R.-Aufnahme. Abgeschliffene Oberfläche in der Nähe des Periproct; a: „Bälkchenstruktur" des Kalkskelettes; b: synchrones Auftreten von etwa 100 skelettbildenden Zellen aus der Tiefe des Kalkskelettes der Schale, erkennbar an den hellen Kalkkristallen im Innern. Auflichtbeleuchtung (Ultropak $55 \times$; E. LerTz). 50 Minuten nach a beginnt die Zusammenballung der Zellen: $c$ und das Zusammenwachsen der Kristalle: d bis g. Das geballte Kalkmaterial wird allmählich in die Tiefe verlagert und mit Kalktrümmern verbunden; $h$. Die tiefschwarzen Gebilde sind rotbraune Amoebocyten, teils noch unter den Kalkbälkchen, teils an der Oberfläche. Unter Z.R. lebhafte Bewegung der zur Skelettoberfläche gelangten "Schübe" von kristallführenden Zellen

Diese Tatsachen führen zu der Überlegung, ob der Einbau von Mikro-Kalktrümmern in die Wunde infolge eines gerichteten Transportes durch die langsamen Bewegungen der lebenden Plasmanetze, denen die Teilchen aufgelagert sind, erfolgt, oder ob bei diesem beachtlichen Vorgang allein der Zufall entscheidet.

Wie bereits betont, eignen sich die meist völlig unregelmäßig gestalteten MikroKalktrümmer sehr wenig für eine genaue Teilbildanalyse von Z.R.-Aufnahmen dieser Bewegungsvorgänge, so dringend erforderlich sie wäre für eine eindeutige Beantwortung der Frage, ob gerichtete oder regellose Bewegung vorliegt. Nur eine statistisch gesicherte Bewegungsanalyse könnte hier helfen; hierfür sind jedoch keine technisch durch- 
führbaren Bedingungen gegeben. Es können daher zunächst nur - mit der nötigen Vorsicht - die zahlreichen vorliegenden Z.R.-Laufbilder herangezogen werden, deren häufige Beobachtung folgende gesicherte Befunde ergibt:

1. Eine abgeschabte oder abgeschliffene kleine Fläche der Skelettoberfläche, bei der die Feinstrukturen des Kalkskelettes mit seinem "Doppel-T-Trägerprinzip" freigelegt sind, kann innerhalb von 7 bis 8 Stunden nach der Verletzung wieder eine völlig glatte Oberfläche aufweisen. Es werden offensichtlich kleine, in die Mikro-Zwischenräume passende, trotz Abspülens des Versuchsfeldes übriggebliebene Teilchen infolge der Tätigkeit der netz- und skelettbildenden Coelomzellen mit eingebaut. An einigen MikroZ.R.-Aufnahmen konnte das langsame, aktive Emporsteigen skelettbildender Coelomzellen aus den "Maschen" des Kalkpanzers im Z.R.-Laufbild beobachtet werden. Diese Zellen tragen im Innern einen Kalkkristall. Der Vorgang ist sehr beachtlich, vor allem die sehr deutliche, bald nach dem "Auftauchen" aus der Tiefe einsetzende Vereinigung dieser Zellelemente zu verschieden großen Aggregaten, in denen die Zusammenfügung des intrazellulären Kalkmaterials zu größeren Einheiten erfolgt, sowie die interessante Einbeziehung und Verwendung der hier zufällig vorliegenden Mikro-Kalktrümmer.

Abbildung 9 zeigt den selten zu beobachtenden Vorgang des „schubweisen“ Aufsteigens von etwa 100 skelettbildenden Zellen aus dem Kalkskelett der Schale von Psammechinus miliaris im Auflicht (Ultropak-Z.R.-Aufnahme). a: Das „Bälkchenwerk" des Schalenskelettes ist deutlich erkennbar. Etwa 10 rotbraune Amoebocyten liegen dicht unter der Skelettoberfläche in den Zwischenräumen des Kalkskelettes. b: Ein "Schub" von etwa 100 Zellen mit einem Kalkkristall im Innern taucht aus der Tiefe auf, c: 25 Minuten später (50. Minute nach Versuchsbeginn) beginnt die Zusammenballung der Zellen; im Teilbild als kompaktere weiße Gebilde erkennbar, besonders detutlich in der Mitte oben im Bilde. d: Nach weiteren 12 Minuten setzt auch seitlich und unten die Zusammenballung und „Verlötung“ der Kristalle ein. e: 42 Minuten später sind kaum noch Einzelzellen mit Kalkkristall-Einschlüssen sichtbar. f und g: Die Zusammenballung ist weiter fortgeschritten. h: 175 Minuten nach Auftauchen der kalkführenden Zellen (b) werden die neu entstandenen größeren Kalkteile in die Tiefe verlagert. Die „Mikro-Verletzungen“ der Bälkchenstruktur sind zum Teil bereits ausgeglichen.

2. Die passiven Ortsverlagerungen der größeren Kalkpartikel sind, wie oben bereits erwähnt, hinsichtlich etwaiger Gesetzmäßigkeiten in bezug auf Richtung und Ort des Einbaues besonders kritisch zu betrachten. Die großen Verschiedenheiten der im Z.R.-Laufbild zu beobachtenden Bewregungsrichtungen lassen auch bei noch so häufigem Studium des Laufbildes keine Bevorzugung irgendeiner Richtung erkennen. Einwandfrei steht fest, daß nach einigen Stunden die Kratzer mit verschieden großen Kalktrümmern ausgefüllt sind, die dann durch neue Kalkelemente untereinander verbunden werden (Aufhören der passiven Bewegung).

Normalerweise vollzieht sich die Heilung von Verletzungen bei $P_{\text {sammedinus }}$ miliaris unter dem schützenden, relativ schnell gebildeten primären Wundverschluß; dieser Prozeß ist daher leider einer direkten Beobachtung entzogen. Die Versuche an explantierten Teilen des primären Wundverschlusses im durchfallenden Licht sowie die Beobachtungen an kleinen Sekundärverletzungen können wenigstens zum Teil einen Aufschluß über die Dynamik der auf langsamen Bewegungen im Protoplasma der netz- 
bildenden Zellen in der Coelomflüssigkeit beruhenden Materialverlagerungen in Wundnähe geben.

Wesentlich ist die Tatsache, daß nach dem Setzen von kleinen Sekundärverletzungen mit der Nadel herausgerissene Kalktrümmer in der Wundrinne eingebaut werden können, wodurch die Heilung und Glättung der Skelettoberfläche erheblich schneller vonstatten geht, als wenn die Wunde nur mit neuem Kalkmaterial geschlossen werden mïßte, das erst durch aktive Zuwanderung von skelettbildenden Coelomzellen aus dem Skelettgewölbe des Seeigels herbeigeschaff und gemäß der „erblichen Reaktionsnorm“ zusammengebaut werden müßte.

Es ist zunächst anzunehmen, daß das lose Kalkmaterial infolge richtungsloser Kontraktionen und Dilatationen der plasmatischen Netze zufällig in die Vertiefungen der kleinen Verletzungen gelangt und dann für den Heilungsprozeß mitverwandt wird. Es wäre unzulässig, hier hypothetisch ein gerichtetes Bewegungsverhalten der netzbildenden Coelomzellen anzunehmen, so verführerisch dies auch sein könnte.

Bringt man auf die Kratzer fein zerriebene Kalkteilchen aus dem Skelett eines anderen Tieres der gleichen Art, so zeigt sich das gleiche Verhalten: Das Material wird teilweise eingebaut. Auch kleinste Partikel von Miesmuschelschalen, in Wundnähe gebracht, gelangen zusammen mit den eigenen Kalkteilchen zufällig in die Rillen und scheinen - soweit das Z.R.-Laufbild eine Deutung zuläßt - nicht abgestoßen zu werden.

Es ergibt sich die Frage, ob der den Heilungsvorgang offensichtlich beschleunigende „Einbau“ zufällig in die Wunde gelangter kleiner Kalktrümmer temporär oder permanent ist. In Anbetracht der erheblichen Störung des Kristallfeinbaues in der Wundregion ist eine nur temporäre Verwendung der kleinen Kalktrümmer in der Wunde durchaus möglich; wie der Ersatz des also möglicherweise nur provisorisch eingebauten Materials erfolgt, müßte eine weitere Untersuchung klarstellen. Von besonderem Interesse wäre ferner die Anwendung der Z.R. bei der Neubildung eines Stachels mit der charakteristischen Kannelierung seiner Oberfläche. Relativ frühzeitig einsetzende Bewegungen des Regenerates verhindern leider derartige Aufnahmen.

\section{ZUSAMMENFASSUNG}

1. Das Bewegungsverhalten der Coelomzellen des Echinoiden Psammechinus miliaris GMEL. wird an kleinen von Stacheln, Füßchen und Pedicellarien befreiten Stellen der Skelettoberfläche in Periproctnähe untersucht.

2. Aus dem freiliegenden „Bälkchenwerk" treten Coelomzellen aus, von denen nur die rotbraunen Amoebocyten auf dem hellen Kalkuntergrund im Auflicht (Ultropak; E. LeITZ) sichtbar sind.

3. Nach einigen Stunden ist die Wundfläche mit einer dicken rötlichen Zellmasse bedeckt, dem "primären Wundverschluß". Außer den Coelomzellen enthält der Wundverschluß noch verschieden große Kalkpartikel, die vom Abschleifen der Versuchsstelle herrïhren.

4. Bei direkter Beobachtung ist weder an den rotbraunen Amoebocyten noch am Wundverschluß die geringste Bewegung zu erkennen.

5. Zeitrransformation (Zeitraffung [Z.R.] auf $1 / 240$ und $1 / 480$ ) zeigt die mit erheblicher Ortsverlagerung und Metabolie verbundene Bewegung der allein wahrnehm- 
baren rotbraunen Amoebocyten auf der Wundfläche. Im scheinbar in Ruhe befindlichen Wundverschluß findet eine ständig hin- und herwogende Bewegung der "Zell-Kalkmasse" statt.

6. Bereits nach 6 bis 7 Stunden ist das Operationsfeld völlig geglättet; die Lücken im Kalkskelett sind kaum noch zu erkennen infolge der „neu eingebauten“ Kalkelemente. Die eigentlichen Heilungsvorgänge (Wiederherstellung der Feinstruktur des Kalkskelettes) erfolgen unterhalb des primären Wundverschlusses, sind also nicht der Beobachtung zugängig.

7. Wird der primäre Wundverschluß im ganzen vorsichtig abgehoben und zerzupf, so kann das Bewegungsverhalten der entstandenen kleinen und großen "Aggregate“ im Durchlicht unter Z.R. untersucht werden.

8. Die im zerriebenen Explantat erhaltenen Coelomzell-Aggregate aller Größen weisen erhebliche Ortsveränderungen auf; oft breiten sie sich langsam aus unter Auswanderung zahlreider randlich liegender Zellen. An den Außenzonen mittlerer und großer Aggregate werden plasmatische Netze sichtbar, die ständig ihre Gestalt und Maschenweite ändern.

9. Diese Plasma-Netze bilden die Grundlage der Aggregate; ihre Kontraktionen und Dilatationen bewirken die Ortsverlagerungen der Aggregate ("Netzbildende Coelomzellen"; KuHL 1937).

10. Wenigzellige Aggregate vereinigen sich in den allermeisten Fällen, sobald ein gewisser Abstand überbrückt ist. Mittlere und große Aggregate gehen häufig eine Verbindung ein; meist werden vorher lockere Coelomzell-Brücken hergestellt. In manchen Fällen gleiten die Aggregate aneinander vorbei.

11. Im polarisierten Licht lassen sich bei gekreuzten Nicols die ersten kleinen neugebildeten Kalkkristalle in den skelettbildenden Coelomzellen ( $=$ netzbildenden Zellen) nachweisen.

12. Der Verschluß kleiner Kratzwunden im noch dünnen primären Wundverschluß (die Kratzer dringen bis zur abgeschliffenen Skelettoberfläche vor) wird unter Z.R. im Ultropak-Auflicht untersucht. Die Ergebnisse am explantierten Wundverschluß im Durchlicht führen zum Verständnis der Bewegungsvorgänge im ungewohnten Auflicht.

13. Im zunächst verwirrenden Bewegungsgeschehen (die auffälligen rotbraunen Amoebocyten haben bei der Wundheilung keine Funktion) fallen die durch die Operationsnadel herausgerissenen kleinen Kalktrümmer auf; sie werden passiv durch die Plasmanetze bewregt, gelangen auch zufällig in die Kratzer und werden an den Rändern durch neugebildetes Kalkmaterial festgelegt oder eingebaut. Aus der Tiefe der Kratzer können lose Kalkpartikel heraufbefördert werden; auch diese werden häufig eingebaut. Die entstehenden Kalkbrïcken werden schließlich untereinander verbunden und dadurch die kleine Wunde verschlossen. Das eingebaute Kalkmaterial zeigt auch unter starker Z.R. keine passive Bewegung mehr.

14. In seltenen Fällen kann der Vorgang des „schubweisen“ Aufsteigens der skelettbildender Zellen aus dem Panzer und ihre Zusammenballung im Z.R.-Laufbild beobachtet werden.

15. Ob der Einbau von herausgerissenem Kalkmaterial temporär oder dauernd ist, muß noch geprüft werden. 


\section{ZITIERTE LITERATUR}

Kura, W., 1937. Die Zellelemente in der Leibeshöhlenflüssigkeit des Seeigels Psammechinus miliaris GmEL. und ihr bewegungsphysiologisches Verhalten. (Eine MikrozeitrafferfilmAnalyse.) Z. Zellforsch. mikrosk. Anat. 27, 1-13.

- 1937. Die Zellelemente in der Leibeshöhlenflüssigkeit des Seeigels Psammechinus miliaris GMEL. In: Beiheft zum Hochschulfilm Nr C 230.

- 1949. Die technischen Grundlagen der Kinematischen Zellforschung. Vorschläge für eine exakte wissenschaftliche Kinematographie. Springer, Berlin, 185 pp.

- 1950. Kinematische Zellforschung durch Anderung des Zeitmomentes mit Hilfe des Zeitrafferfilmes. Zool. Anz. (Suppl. Bd) 15, 10-43.

Schinke, H., 1948. Bildung und Ersatz der Zellelemente der Leibeshöhlenflüssigkeit von Psammechinus miliaris (Echinoidea). $66 \mathrm{gez}$. Bl. (Weitere Literaturangaben daselbst.) Münster, Math.nat. Diss. v. 31. März 1949. 